\author{
What motivates dentists after qualification has \\ very little to do with what motivated them to \\ choose dentistry in the first place.
}

\title{
OPINION
}

\section{Why become a dentist?}

Why did you become a dentist? If the findings of the study in the last issue of the $B D J$ (BDJ 2002; 193: 471473) are to be believed, it was because you were interested in security, personal and financial gain. Strong words indeed.

My choice of words in the paragraph above was deliberately provocative and possibly unfair to the authors of the paper who do not draw the concusion I have suggested, but definitely do hint it. Their research compared the motivation of dental and medical students towards the career of their choice, and thus was a comparative study. They imply that dental students are more likely to be motivated by security, personal and financial gain than medical students, but this is a comparison rather than a bald fact and needs to be interpreted as such. However it does raise the question why do people become dentists?

After all, I, like many others, was often asked why I had chosen to be someone disliked by most people (a popular misconception I told myself) involved in 'poking around inside people's mouths'. Some people kindly added that they supposed it was better than a parking meter attendant, a tax inspector or an estate agent, but they still expressed a mystification as to why anyone would want to do it. My usual reply was that the reality of being a dentist was completely different from my perception before I started training (whatever that meant) and hoped they would not enquire further.

As a dental student I would sometimes engage in discussion with my fellow students as to why we had chosen dentistry, and my recollection of the reasons we admitted to each other (probably more honest than those we admitted to strangers) was a desire to control our own working lives, an interest in working with our hands, the satisfaction of treating patients almost entirely ourselves (instead of referring on as we perceived doctors did) and most of all the freedom that we assumed dentistry would give us in the future.

Some of this agrees with the findings of the research in the paper which revealed that dental students claimed they were motivated by status, security, self employment and working conditions, whereas medical students claimed they were more interested in career opportunities, patient care and working with people. However, as the authors point out, the study is only a snapshot of a small number of students.

The truth or otherwise of these suggestions for motivation of career choice will doubtless reinforce or upset the current assumptions many people have. Some people will eagerly proclaim the accuracy of the findings and point to the "Call Me Doctor" campaign as evidence of a desire for status and the lifestyle of various dentists as evidence of the desire for a high income. Others will just as strongly oppose the findings, citing dentists they know on low incomes who provide a caring service for the community which demonstrates a definite desire to focus on patient care and working with people.

However, all of this is missing the point. What motivates dentists after qualification has very little to do with what motivated them to choose dentistry in the first place. After all, who ever enters any career (or job) with even an inkling of an idea of what is really involved? The question really is why do we choose to enter a particular career such as dentistry? From this we can move to a second question: is the motivation the same or does it change as we begin our dental studies? And the third question, which this research focused on, is whether there is a difference between people who want to be doctors and people who want to be dentists? Finally, a fourth question (which one hardly dares to ask) is: does it matter anyway?

I would suggest it does matter. If prospective doctors and dentists are indeed motivated by different things then careers advice and promotion needs to be different to attract the appropriate people. Perhaps people who started off as prospective medical students and then ended up choosing dentistry because of various circumstances should be cautioned more as to the differences in the two careers? Perhaps more should be done to check that prospective dental students are suited to the job?

We must remember in all of this that it assumes this research is true, and the authors themselves caution against this. The other question we need to ask is whether the motivation of dental students today is relevant to the world of dentistry we see for tomorrow, which will be very different.

Mike Grace m.grace@bda-dentistry.org.uk 